Bull. Egypt. Soc. Physiol. Sci. Vol. (41) Issue (3), 296-315

\author{
Bull. of Egyp. Soc. Physiol. Sci. \\ (Official Journal of Egyptian Society for Physiological Sciences) \\ (pISSN: 1110-0842; eISSN: 2356-9514)
}

\title{
Flaxseed Oil Supplementation Afford Comparable Therapeutic effect to Metformin in Bleomycin Induced Pulmonary Fibrosis Rat model
}

\author{
Eman Kolieb ${ }^{1}$, Shymaa Ahmed Maher ${ }^{2}$, Karima El-Sayed ${ }^{1}$ \\ ${ }^{1}$ Physiology Department, Suez Canal University, Ismailia, 41522, Egypt. \\ ${ }^{2}$ Biochemistry Department, Suez Canal University, Ismailia, 41522, Egypt.
}

Submit Date: August 7, 2020

Accept Date: Oct 22, 2020

Available Online: Feb 1, 2021

\section{Keywords}

- Pulmonary fibrosis

- Metformin

- $\quad$ Flaxseed oil,

- Bleomycin

- NOX4

\begin{abstract}
Background: Pulmonary Fibrosis is a chronic lung disease characterized by scar formation and respiratory insufficiency. Metformin is an antidiabetic drug that has recently been shown to prevent lung fibrosis via NADPH oxidase-4 suppression. Flaxseed oil has been shown to be a potent antioxidant that attenuates oxidative damage by inhibition of lipid peroxidation and the proinflammatory cytokine production of IL-6 and TNF-alpha. Aim: To investigate whether metformin and/or flaxseed oil could protect against bleomycin-induced pulmonary fibrosis and if this protection is mediated by inhibiting NOX-4 signaling pathway and the synthesis and release of inflammatory and oxidative stress markers. Material and Methods: Fifty adult male rats were randomized into 5 groups/10 rats each. Pulmonary fibrosis was induced by Bleomycin, delivered intratracheally at a concentration of $1.5 \mathrm{mg} / \mathrm{kg}$ body weight once in group PF, MET, Flax and combined MET\& Flax. Both metformin and Flaxseed oil were administered orally for 21 day after induction of PF. Withdrawal of blood samples for chemical and spectral assay of antioxidant markers was done. Histopathology and assessment of inflammatory and fibrotic markers and PCR expression of NOX4 gene were done. Results: There was a significant reduction in inflammatory cell count, histopathological score of inflammation and fibrosis in the three treatment groups. Also, there was marked improvement in inflammatory (IL-6, TNF-a) and fibrotic markers (TGFB and Col-1) in metformin group rather than flaxseed and combined group. Nox4 gene expression was significantly reduced in metformin treated group rather than other 2 groups
\end{abstract}

Corresponding author: Karima El-Sayed Ismail Ahmed, Physiology Department, Suez Canal University, Ismailia, 41111, Egypt. E-mail: karima_ahmed@med.suez.edu.eg. Phone number: +201003541288 


\section{INTRODUCTION}

Pulmonary fibrosis (PF) is the squeal of lung injury, which can result from severe infections, radiation, chemotherapy, environmental exposures or unknown etiologies. In response to injury, tissue remodeling and formation of fibrotic scars are initiated and enhanced by mechanical and chemical factors, such as transforming growth factor beta (TGF- $\beta$ ) which stimulates anabolic metabolism in activated myofibroblasts (1).

Bleomycin (BLE) is a group of glycopeptides that binds iron and oxygen in vivo to produce an active drug, effective in cancer treatment. $18 \%$ of patients treated with bleomycin have developed pulmonary toxicity. bleomycin's fibrotic side effects are so common that it is widely used to create animal models of pulmonary fibrosis (2).

The chemotherapeutic mechanism of pulmonary fibrosis results from the chelation of iron ions with oxygen, which leads to production of superoxide and hydroxide free radicals. The increased production of reactive oxygen species (ROS) is critical in producing proinflammatory mediators as IL-6 and TNF-- $\alpha$ that lead to bleomycin's pulmonary toxicity, and lead to lung fibrosis (3).

Metformin (MET) is a safe and widely used treatment for non-insulin-dependent diabetes, and has therapeutic potential to restore glucose and lipid metabolic homeostasis. Metformin recently shown to prevent lung fibrosis via NADPH oxidase-4 (NOX4) suppression and amelioration in the inflammatory profibrotic response found in pulmonary fibrosis (4). NOX4 suppression inhibits myofibroblast differentiation by TGF- $\beta$, supporting a preventive role in the development of fibrosis (5).
Flaxseed oil has been shown to be a potent antioxidant, it attenuates oxidative damage effectively due to their protective antioxidant properties. This can protect against lung pulmonary fibrosis in bleomycin-induced lung fibrosis (6). Flaxseed oil also inhibits lipid peroxidation by inhibiting the proinflammatory cytokine production of IL-6 and TNF- $\alpha$ (7).

We aim in this study to compare the therapeutic effect of metformin, flaxseed oil or combined treatment, in resolution of bleomycin induced lung fibrosis model, and to investigate if this therapeutic effect is due to NOX4 suppression.

\section{Materials:}

\section{1-Animals:}

Fifty adult male Albino rats weighing average of 200-250gm, 8-month old were used in this study. Animals were purchased from the animal house in faculty of Veterinary Medicine, SCU, Egypt; they were housed in the Physiology department, Faculty of Medicine, Suez Canal University in spacious plastic cages (5 rats/ cage) at controlled room temperature and were kept with free access to standard rat chow diet and tap water. They were left for acclimatization for one week before the start of the study.

\section{2-Ethics statement}

All experimental procedures on animals that were used for this study had followed the standards of the Research Ethics Committee of the Faculty of Medicine, Suez Canal University.

Animals were handled gently, housed with suitable environmental and nutritional conditions, assessed for general health and body weight and anesthetized with ethyl alcohol before injury and before scarification. 
3- Drugs and chemicals

1- The drugs used for the study were bleomycin sulphate, metformin hydrochloride and flaxseed oil.

Bleomycin sulphate USP injection (15 units) was purchased from CiplaLTD. Verna Industrial Estate, Goa 403722, IndiaReg No.24074/2005. Metformin hydrochloride $1000 \mathrm{mg}$, is a white and odorless powder for oral solution in sachets. Metformin hydrochloride was obtained from SEDICO, Egypt. Carboxymethyl cellulose (CMC) was obtained from Sigma. Metformin was freshly dissolved in distilled water. I3C was suspended in 0.5\% CMC solution. Flaxseed oil was purchased from Pimus pharmaceutical Inc. (Scottsdale, AZ, USA).

\section{2- Reagents for detection of PCR expression of NOX-4 gene:}

Total RNA was extracted from lung tissues using RNeasy Mini Kit (cat no 74104, Qiagen). RNA was quantified using Nanodrop 8000(Thermo Scientific USA) and reverse transcribed using (QuantiTect Reverse Transcription Kit cat no205311, Qiagen). PCR was performed with an ABI PRISM 7000 Sequence Detector System (Applied Bio system step1plus) and SYBR Green (QuantiTect SYBR Green PCR Kit cat no.204141, Qiagen) according to the manufacturers' instructions, using specific sequence primers: NOX4 (QuantiTect primer assay, Qiagen, Cat no: QT00186550) and B-actin (QuantiTect primer assay, Qiagen, Cat no: QT00193473).

\section{4- Study groups:}

The rats were divided into four experimental groups (10 rats/ group), the total duration of the study was 24 days.
Group 1 (control group, CTL): Rats in this group were fed with normal chow diet and received 0.1 $\mathrm{ml}$ of normal saline intratracheal instead of bleomycin then, rats received $0.2 \mathrm{ml}$ of $0.5 \%$ carboxymethylcellulose (CMC) orally once daily for 21 days.

Group 2 (Pulmonary fibrosis, PF): Rats in this group were anesthetized by inhalation of ether and then had received bleomycin sulphate by intratracheal instillation at a dose of $(1.5 \mathrm{mg} / \mathrm{kg}$ body weight in $0.25 \mathrm{ml}$ phosphate buffered saline) as a single dose only to induce pulmonary fibrosis (8). The day of administration was considered day 0 .

Group 3 (metformin treated group, MET): Rats in this group had received bleomycin sulphate by intra-tracheal instillation as a single dose only as in G2 then were treated with metformin after 3 days from bleomycin administration and was continued for 21 days, metformin was given orally by gavage at the dose of $500 \mathrm{mg} / \mathrm{kg} /$ day was dissolved in $0.5 \%$ carboxymethylcellulose (CMC) (9).

Group 4 (flaxseed oil treated group)(Flax): Rats in this group received bleomycin sulphate by intratracheal instillation as a single dose only as in G2 then were treated with flaxseed oil $(2 \mathrm{ml} / \mathrm{kg}$ once a day) by oral gavage after 3 days from bleomycin administration and was continued for 21 days( 10)

Group 5 (pulmonary fibrosis, treated with both metformin and flaxseed oil group) (PF, combined MET+Flax): Rats in this group had received bleomycin sulphate by intra-tracheal instillation as a single dose only as in G2 then was treated with both flaxseed oil and metformin, after 3 days from bleomycin injection and was continued for 21 days. 


\section{5- Evaluation parameters}

\section{a. Broncho alveolar lavage fluid (BALF) analysis}

At the end of the study rats were anesthetized intra-peritoneally with pentobarbitone sodium (60 $\mathrm{mg} / \mathrm{kg}$ ), trachea was cannulated with a blunt needle attached by a syringe to perform bronchoalveolar lavage (BAL) by the injection of $3 \mathrm{ml}$ saline (three times, total $9 \mathrm{ml}$ ) followed by gentle aspiration of the fluid from the lung. The BALF was done within 2 hours of taking out the samples; it was analyzed for total inflammatory cell count and differential cell count (lymphocytes and neutrophils). Total cell count was made in a haemocytometer. Differential cell counts were estimated from cytospine preparations by counting 300 cells stained with May-Grünwald-Giemsa $(11,9)$.

- Blood samples were collected via puncture of retro-orbital venous plexus, serum were separated and used immediately for biochemical assessments Later on, thorax was opened to dissect out lungs and then they were weighed. Left lung was kept in formalin for histopathology and right lung was stored at $-80{ }^{\circ} \mathrm{C}$ for biochemical and molecular estimation of various parameters.

\section{$b$-Assessment of lung structure and}

\section{function:}

- Lung histopathological examination: Left lungs were fixed in $4 \%$ paraformaldehyde for histological studies. After fixation for 2 days in neutral buffered formalin, lung tissues were taken out and embedded in paraffin wax, cut into $4 \mu \mathrm{m}$ sections and stained separately with haematoxylineosin (H\&E) and Masson'strichrome (MT) stains. The degree of inflammation and tissue damage were noted in $H \& E$ stained sections while the degree of fibrosis was graded and scored as per Ashcroft score from MT stained sections (12).

Histological grading of lesions was performed using a blinded semi-quantitative scoring system at a magnification of $100 x$ by using an Olympus microscope (Olympus, Tokyo, Japan). The severity of inflammation was estimated using the semi-quantitative grading system which considers the following categories: Grade 0, absence of inflammation; Grade 1, minimal inflammation; Grade 2, minimal to moderate inflammation; Grade 3, moderate inflammation with thickening of alveolar walls; Grade 4, moderate to severe inflammation; and Grade 5, severe inflammation with presence of follicles which replace the parenchyma. The severity of interstitial fibrosis was also determined using the semi-quantitative grading system described by Ashcroft et al. and modified by Ralf-HartoHübner et al. The entire lung section was observed at a $\times 100$ magnification and a score ranging from 0 (normal lung) to 8 (total fibrosis) $(13,14)$.

The criteria for grading lung fibrosis were as follows:

Grade 0: Normal lung. Grade 1: Minimal fibrous thickening of alveolar or bronchiolar walls. Grade 2-3: Moderate thickening of walls without obvious damage to lung architecture. Grade 4-5: Increased fibrosis with definite damage to lung structure and formation of fibrous bands or small fibrous masses. Grade 6-7: severe distortion of structure and large fibrous areas; "honeycomb lung" was placed in this category. Grade 8: total fibrous obliteration of fields. The mean score of all fields was taken as the fibrosis score of that lung section 
- Spectral assay of antioxidant markers:

Lung tissue malondialdehyde (MDA) and Reduced Glutathione (GSP) levels were measured using a colorimetric assay. Tissue MDA was assessed using kits supplied by Sigma Aldrich Co., USA, according to the instructions of the manufacturer and GSP kits supplied by Sigma Aldrich Co., USA (15).

\section{- Estimation of fibrotic and inflammatory markers}

Tissue concentration of inflammatory markers as IL-6 was determined using ELISA kits supplied by abcam, Cairo, Egypt, product number ab100772. Tissue concentration of $\mathrm{TNF}-\alpha$ was determined using ELISA kits purchased from, abcam, Cairo, Egypt, product number: ab46070).

Tissue concentrations of fibrotic markers (TGF- $\beta$ ) in the lungs tissue homogenate was measured using ELISA supplied from USCN, United Kingdom, TGF-b1 ELISA kit for rats, product number: SEA124Ra) according to the manufacturer's instructions. Tissue concentrations of type I collagen in the lungs tissue homogenate was measured using ELISA was purchased from, Sigma Aldrech, Cairo, Egypt. Manufactured by Chongqing Biospes Co, BYEK1478. China.

\section{Quantitative RT-PCR detection of NOX 4 gene in} lung tissue.

Total RNA was extracted from lung tissues using RNeasy Mini Kit (cat no 74104, Qiagen) according to the manufacturer's instructions. RNA was quantified using Nanodrop 8000(Thermo Scientific USA) and reverse transcribed using (QuantiTect Reverse Transcription Kit cat no205311, Qiagen). PCR was performed with an ABI PRISM 7000 Sequence Detector System (Applied Bio system step1plus) and SYBR Green (QuantiTect SYBR
Green PCR Kit cat no.204141, Qiagen) according to the manufacturers' instructions, using specific sequence primers: NOX4 (QuantiTect primer assay, Qiagen, Cat no: QT00186550) and B-actin (QuantiTect primer assay, Qiagen, Cat no: QT00193473). The results were analyzed using the $2-\Delta \Delta \mathrm{Ct}$ method of analysis as described by Livak and Schmittgen(16).

\section{6-Statistical analysis}

The results are expressed as mean \pm S.D One-way analysis of variance (ANOVA) followed by Benforonie post hoc test was used for analysis of BAL cell count, biochemical and molecular data of all the study groups Statistical analysis will be done with Statistical Package of Social Science (SPSS) software version 20. A value of $p<0.05$ was considered as significant.

\section{Results:}

Effect of treatment with metformin and/or flaxseed oil on general parameters

The effect of bleomycin, metformin and/or flaxseed oil treatment on general parameters had showed that there was no statistically significant difference in body weight between the 5 study groups at the end point of the experiment. At the end point $\mathrm{PF}$ group tend to lose weight while the treatment groups tend to gain weight but the difference between 3 treatment groups wasn't significant (Table 1).

Regarding lung weight to body weight ratio, there was statistically significant elevation in this ratio in PF group compared to normal control group $(p=0.001)$. On the other hand it showed significant reduction in the three treated group compared to $\mathrm{PF}$ group ( $\mathrm{p}=0.001)$. The lung weight/body weight ratio 
showed that the lowest ratio was in metformin treated group $(\mathrm{p}=001)$.

Effect of treatment with metformin and/or flaxseed oil on recruitment of inflammatory cells in the BALF of lungs:

On studying the effect of metformin, flaxseed oil and combined treatment on total and differential number of inflammatory cells in BALF, Bleomycin in PF group induced significant increase in total inflammatory cell count when compared to control group ( $\mathrm{p}=0.001$ ), while treatment with metformin, flaxseed oil and combined treatment reduced count significantly when compared to PF group $(\mathrm{p}=0.001$, $\mathrm{p}=0.005, \mathrm{p}=0.002$ ) respectively. Bleomycin significantly increased the proportion of neutrophils and lymphocyte in BLAF in PF group compared to normal control $(\mathrm{p}=0.001)$, while treatment with metformin, flaxseed oil or both showed significant reduction compared to $\mathrm{PF}$ group, regarding lymphocyte count $(\mathrm{p}=0.001)$, $(\mathrm{p}=0.039),(\mathrm{p}=0.004)$ respectively.

While neutrophil count showed significant reduction compared to PF group with $(\mathrm{p}=0.001)$ for the 3 treatment groups.

However, there was still significant elevation in lymphocyte count in metformin treatment group $(\mathrm{p}=0.017)$, flaxseed group $(\mathrm{p}=.001)$ and combined treatment group $(\mathrm{p}=0,005)$ compared to normal control *. Reduction of neutrophil count in the three treatment groups was insignificant compared to normal control $(p=1)$. Regarding the total inflammatory cell count between groups: metformin treated group showed the lowest count $(\mathrm{p}=001)$. (Table 2).

Table (1): Effect of treatment with metformin and/or flaxseed oil on general parameters

\begin{tabular}{|c|c|c|c|c|c|}
\hline $\begin{array}{c}\text { Group } \\
\text { variable(mean } \pm \text { SD) }\end{array}$ & Control & $\begin{array}{c}\text { Pulmonary } \\
\text { fibrosis(PF) }\end{array}$ & PF-Met & PF-Flax & $\begin{array}{c}\text { combined Met- } \\
\text { Flax }\end{array}$ \\
\hline $\begin{array}{c}\text { Body weight }(\mathrm{g}) \text { start } \\
\text { point }\end{array}$ & $221.67 \pm 13.87$ & $233.55 \pm 20.7$ & $235.67 \pm 18.36$ & $234.67 \pm 29.9$ & $221.17 \pm 15.14$ \\
\hline $\begin{array}{c}\text { Body weight (g) end } \\
\text { point }\end{array}$ & $230.33 \pm 9.48$ & $206.33 \pm 22.6$ & $228.33 \pm 18.07$ & $241.17 \pm 23.2$ & $225 \pm 11.83$ \\
\hline $\begin{array}{c}\text { Lung weight/body } \\
\text { weight ratio(mg/kg) }\end{array}$ & $0.22 \pm 0.033$ & $4.95 \pm 2.37^{\text {*** }}$ & $0.31 \pm 0.024^{\# \#}$ & $0.33 \pm 0.1^{\# \#}$ & $0.42 \pm 0.16^{\# \#}$ \\
\hline
\end{tabular}

Values are mean $\pm \mathrm{SD}$, statistically significant difference, ${ }^{* *} \mathrm{p}, \# \# \mathrm{p}<0.01,{ }^{*} \mathrm{P},{ }^{\#} \mathrm{P}<0.05\left({ }^{*}\right)$ compared to control group, (\#) compared to pulmonary fibrosis (PF) group, Start point: at the beginning of the experiment before induction of PF. End point: at the end of experiment before scarification of rat, BW body weight. Control: normal group, PF: bleomycin induced pulmonary fibrosis group, met: metformin treated group, Flax: Flaxseed treated group, Met-Flax: combined treatment group.

Table (2): Effect of treatment with metformin and/or flaxseed oil on recruitment of inflammatory cells in the BALF of lungs:

\begin{tabular}{|l|l|l|l|l|l|}
\hline $\begin{array}{l}\text { Group variable } \\
(\text { mean } \pm \text { SD) }\end{array}$ & $\underline{\text { Control }}$ & $\underline{\text { PF }}$ & $\underline{\text { Met }}$ & $\underline{\text { Flax }}$ & $\frac{\underline{\text { PF,Combined }}}{\text { Met-Flax }}$ \\
\hline Total cells $\left(x 10^{6}\right)$ & $0.78 \pm 0.13$ & $4.61 \pm 0.78^{* *}$ & $2.1 \pm 0.88^{\# \#}$ & $2.7 \pm 1.05^{\# \#}$ & $2.57 \pm 0.93$ \\
\hline $\begin{array}{l}\text { Lymphocytes } \\
(x 10)\end{array}$ & $0.43 \pm 0.06$ & $2.9 \pm 0.54^{* *}$ & $1.5 \pm .67^{\# \#}$ & $1.94 \pm .64^{\#}$ & $1.66 \pm 0.54^{\# \#}$ \\
\hline Neutrophil(x10) & $0.18 \pm 0.02$ & $1.7 \pm 0.35^{* *}$ & $0.06 \pm 0.03^{\# \#}$ & $0.07 \pm 0.04^{\# \#}$ & $0.053 \pm 0.025^{\# \#}$ \\
\hline
\end{tabular}

Values are as mean $\pm \mathrm{SD}$, statistically significant difference, ${ }^{* *} \mathrm{p}, \# \# \mathrm{p}<0.01,{ }^{*} \mathrm{P},{ }^{\#} \mathrm{P}<0.05(*)$ compared to control group, (\#) compared to PF group. Control: normal group, PF: bleomycin induced pulmonary fibrosis group, met: metformin treated group, Flax: Flaxseed treated group, Met-Flax: combined treatment group. 
Effect of treatment with metformin and/or flaxseed oil on histopathological changes in the lungs:

Histological studies with $\mathrm{H} \& \mathrm{E}$ stains in control group showed normal lung tissues showing uniform alveoli with thin fibrous septa lined with regular pneumocytes, thin wall septa (blak arrow) and a central uniform small bronchiole with thin fibrous wall (red arrow) (Fig.1a,b). While the plumonary fibrosis (PF) group showed severe chronic inflamamotry infiltration around bronchioles (Black arrow)(Fig.1c), chronic inflammatory cells (Black arrow) and fibrosis (Red arrow)(Fig.1d), chronic inflammatory cells (Black arrows); lymphocytes, macrophages and plasma cells, interspersed with areas of collagen (fibrosis) (Red arrows) (Fig.1e).

Metformin treated group showed significant reduction in the peri-bronchiolar chronic inflamamotry infiltrate (Black arrow), with mild extention into alveoli (Red arrow)(Fig.2 a), There is extension of chronic inflammatory cells into alveolar walls, leading to mild thickening of alveolar septa (Black arrows) (Fig.2 b), with higher magnification of the it showed chronic inflammatory cells (Black arrows); lymphocytes, macrophages and plasma cells, interspersed with areas of collagen (fibrosis) (Red arrows) (Fig.2 c).

Flaxseed treated group shows mild reduction in in the peri-bronchiolar chronic inflamamotry infiltrate (Black arrow) with signifcant extention into alveoli (Red arrows) (Fig.2 d), persistence of peri-bronchiolar inflammation, with significant extension into alveoli (arrow heads) and areas of fibrosis (Red arrows) (Fig.2 e), higher magnification of the previous figure showing chronic inflammatory cells (Black arrows); lymphocytes, macrophages and plasma cells, interspersed with areas of collagen (fibrosis) (Red arrows) (Fig.2 f). The combined treatment group shows uniform lung tissue, alveoli and bronchiole with thin fibrous tissue (Fig.2 g) with significant reduction of the inflammatory infiltrate, mild extension and thickening of alveolar wall.

Histological studies (Masson trichrome stain) for assessment of the degree of lung fibrosis showed that in control group fibrous tissue was only seen around bronchiles (Black arrows) and large blood vessels (Red arrows) with a score of fibrosis +1 (Fig.3 a). Pulmonary fibrosis showed the presence of mild fibrosis around areas of inflammation (Arrow head) (Masson, 40x) with a score of fibrosis +4 (Fig.3b),

Metformin treated group showed that there was mild fibrous expansion around inflamed bronchioles (Black arrow) with extension into nearby alveoli, leading to mild thickening of alveolar septa (Red arrows) with a score of fibrosis +1 (Masson, 10x)(Fig.3 c), while Flaxseed treated group showed that there was moderate fibrous expansion around inflamed bronchioles (Black arrow) with extension into nearby alveoli, leading to thickening of alveolar septa (Red arrows)with a score of fibrosis +3 (Masson, 10x)(Fig 3d). The combined treated group shows that there was moderate fibrous expansion around inflamed bronchioles (Black arrow) with extension into nearby alveoli, leading to thickening of alveolar septa (Red arrows) with a+ 2 score of fibrosis (Masson, 10x) (Fig 3 e, f).

Effect of treatment with metformin and/or flaxseed oil on oxidative and antioxidant state of the lung tissue: 
Malondialdehyde level was significantly increased, while reduced glutathione was significantly reduced in lung tissue after bleomycin induction compared to normal control group $(\mathrm{P}=0.001)$ for both. Treatment with metformin, flaxseed oil or combined treatment decreased MDA level significantly compared to PF group ( $\mathrm{p}=0.005$, $\mathrm{p}=0.012, \mathrm{p}=0.003)$ respectively. The effect of metformin, flaxseed oil and combined metformin flaxseed oil treatment on the level of reduced glutathione showed statistically significant elevation when compared to PF group ( $\mathrm{p}=0.001$, $\mathrm{p}=.029$ and $\mathrm{p}=0.001$ ) respectively. (table 3, figure $4)$.
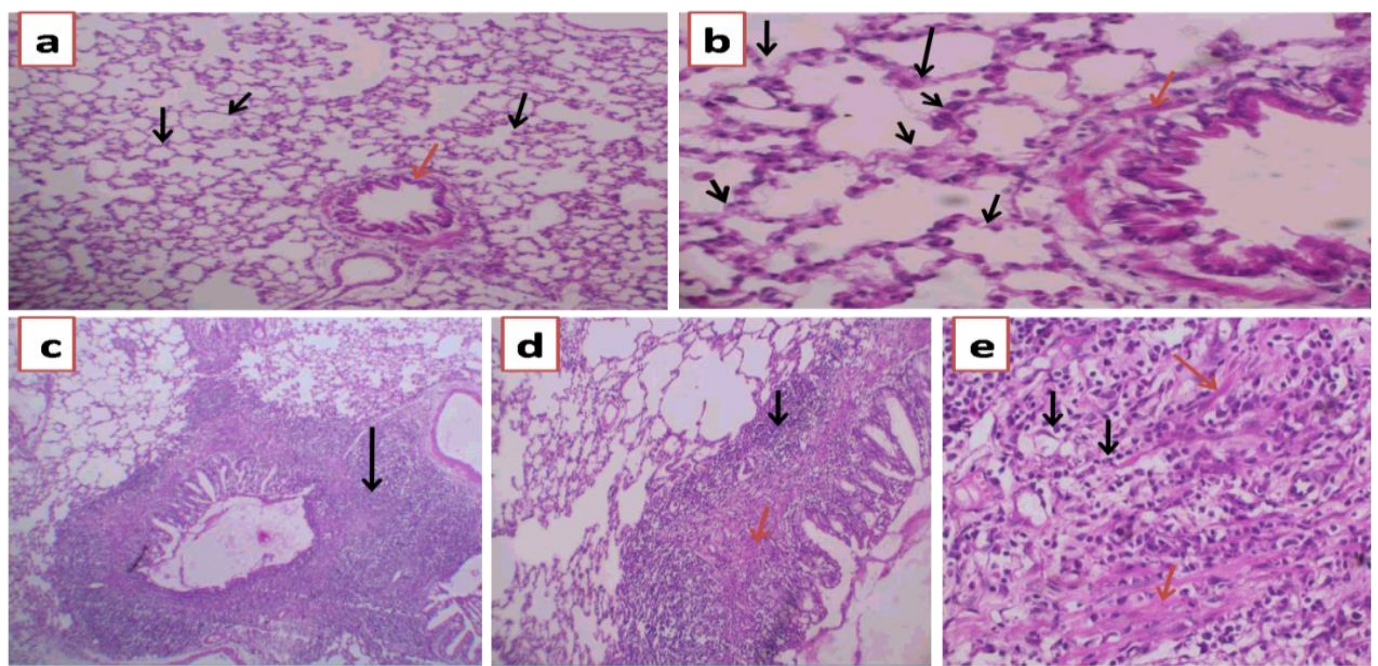

Fig. 1: Lung tissue stained with $H \& E(5 \mathrm{~mm}), \mathbf{a} \& \mathbf{b}$ control group, $\mathbf{c}, \mathbf{d}$ and e pulmonary fibrosis group.
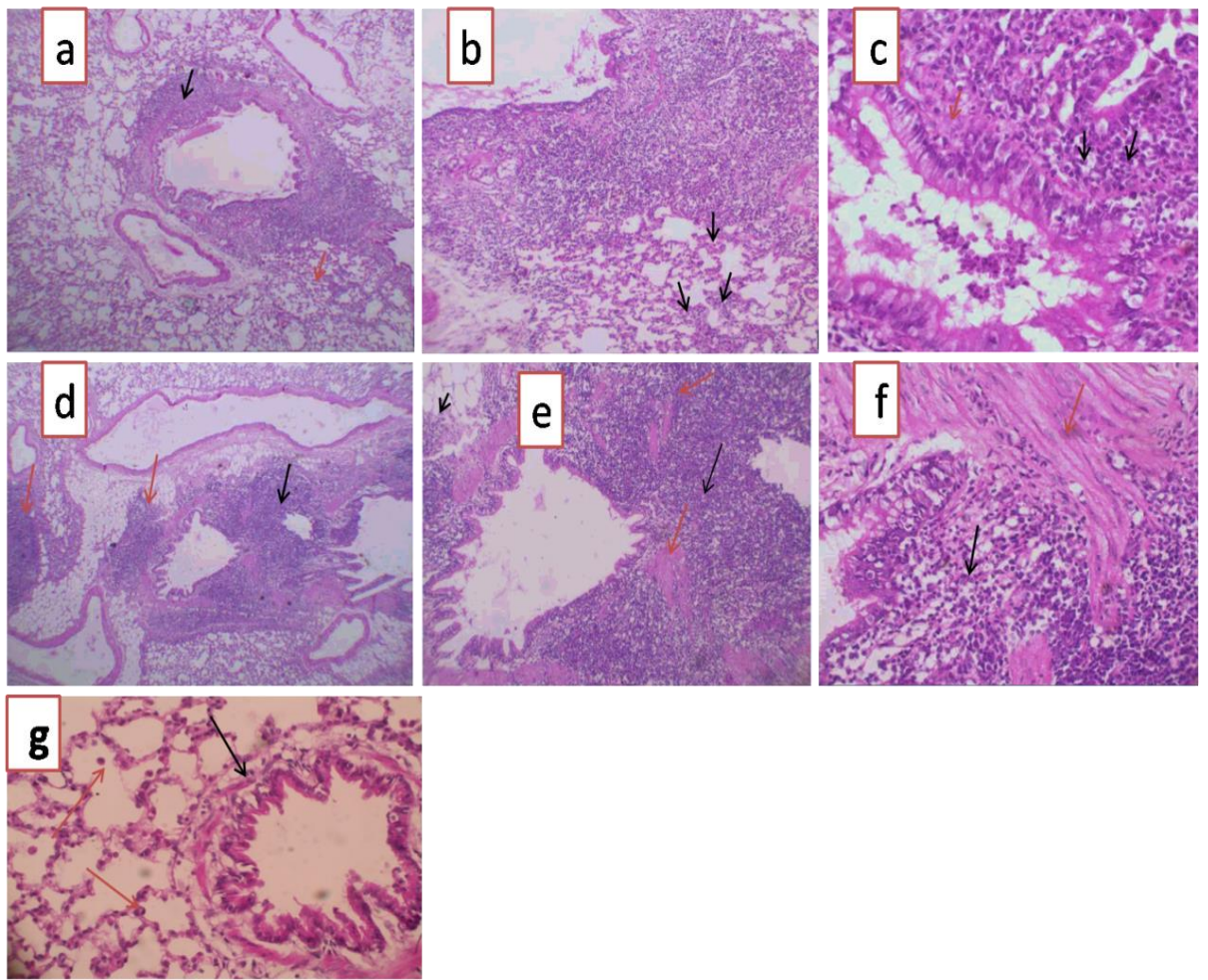

Fig. 2: Lung tissue stained with $\mathrm{H} \& \mathrm{E}(5 \mathrm{~mm})$, a, b and c: metformin treated group D, e, f: flaxseed treated group, g: combined treated group. 


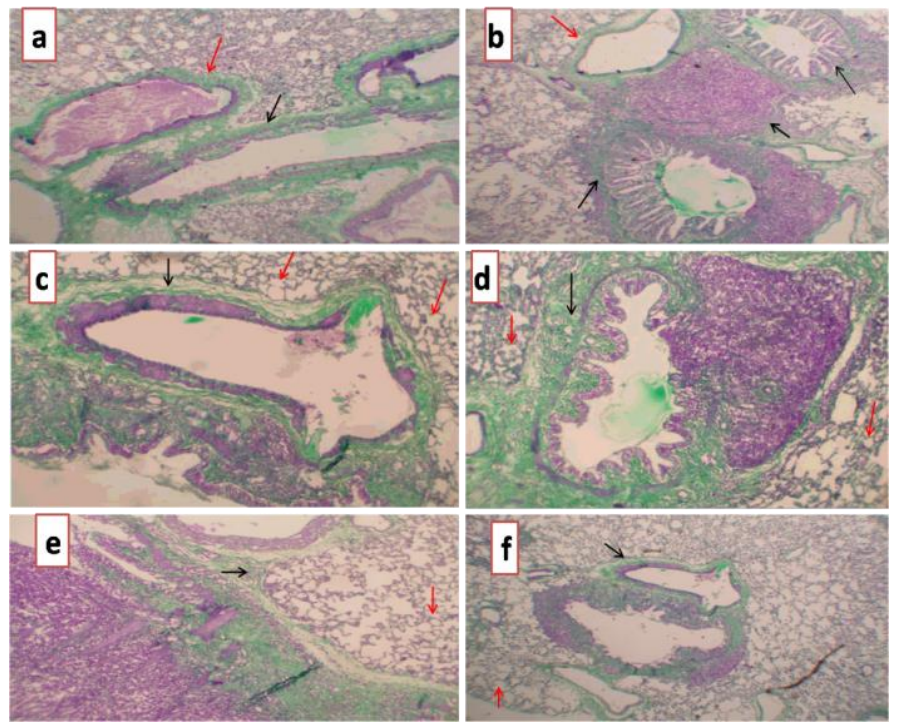

Fig. 3: Lung tissue stained with Masson trichrome $(5 \mathrm{~mm})$. a: normal group, b: pulmonary fibrosis group, c: metformin treated group, $\mathbf{d}$ : flaxseed treated group, $\mathbf{e} \& \mathbf{f}$ : combined treatment group.

Table (3); Effect of treatment with metformin and/or flaxseed oil on oxidative and antioxidant state of the lung tissue:

\begin{tabular}{|l|l|l|l|l|l|}
\hline $\begin{array}{l}\text { Group variable } \\
\text { (mean } \pm \text { SD) }\end{array}$ & $\underline{\text { Control }}$ & $\underline{\text { PF }}$ & $\underline{\text { Met }}$ & $\underline{\text { Flax }}$ & $\underline{\text { PF, Met-Flax }}$ \\
\hline Malondialdhyde(nmol / g) & $\underline{4.34 \pm 2.2}$ & $\underline{15 \pm 4.6^{* *}}$ & $\underline{6.71 \pm 3.34^{\# \#}}$ & $\underline{7.4 \pm 4.4^{\#}}$ & $\underline{6.25 \pm 2.76^{\# \#}}$ \\
\hline$\underline{\text { Reduced glutathione(mg/gm) }}$ & $\underline{15.18 \pm 5}$ & $\underline{1.25 \pm .48^{* *}}$ & $\underline{7.75 \pm 0.75^{\# \#}}$ & $\underline{5.65 \pm 0.51^{\#}}$ & $\underline{7.45 \pm 0.82^{\# \#}}$ \\
\hline
\end{tabular}

Values are as mean $\pm \mathrm{SD}$, statistically significant difference, ${ }^{* *} \mathrm{p}, \# \# \mathrm{p}<0.01,{ }^{*} \mathrm{P},{ }^{\#} \mathrm{P}<0.05(*)$ compared to control group, (\#) compared to PF group. Control: normal group, PF: bleomycin induced pulmonary fibrosis group, met: metformin treated group, Flax: Flaxseed treated group, Met-Flax: combined treatment group.
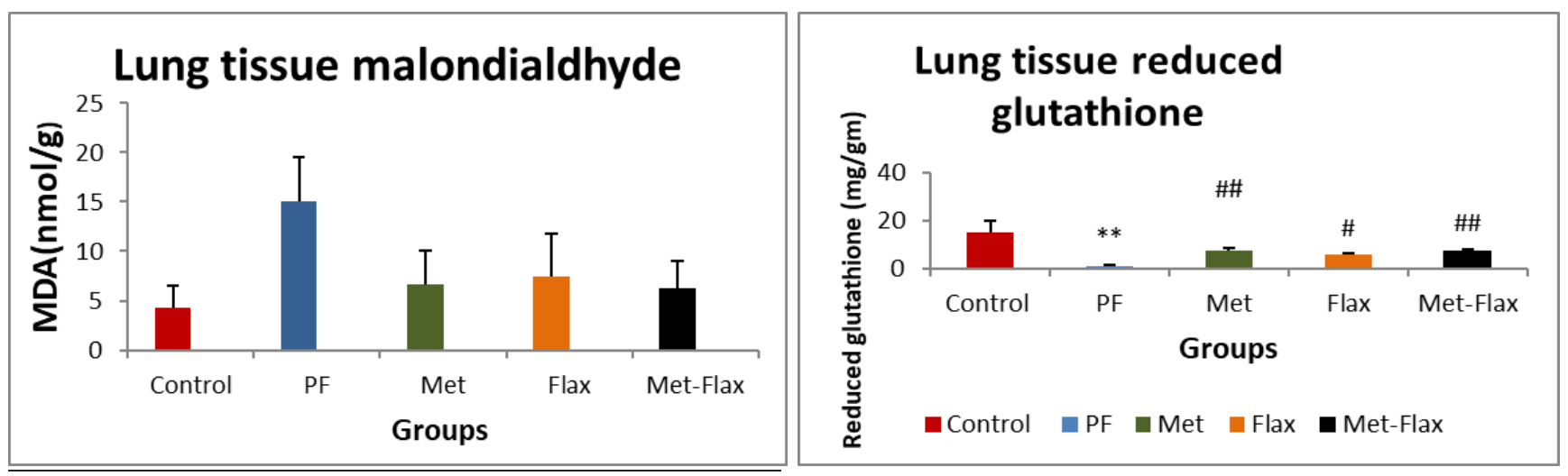

Fig.4 Lung tissue malondialdehyde and reduced glutathione, values are mean $\pm \mathrm{SD}, * * \mathrm{p}, \# \# \mathrm{p}<0.01,\left({ }^{*}\right)$. ${ }^{*} \mathrm{P},{ }^{\#} \mathrm{P}<0.05$ compared to control group, (\#) compared to PF group. Control: normal control group, PF: Bleomycin induced pulmonary fibrosis group, Met: Metformin treated group, Flax: Flaxseed -treated group, Met-Flax: combined treatment group

\section{Effect of treatment with metformin and/or} flaxseed oil on lung tissue homogenate fibrotic markers:

Col-I level showed statistically significant elevation in the $\mathrm{PF}$ group compared to normal control group $(\mathrm{p}=0.001)$ on the other hand all treatment groups showed statistically significant reduction of Col-I compared to PF group ( $\mathrm{p}=0.001)$ for the three treated groups.

While, The fibrotic marker TGF- $\beta$ concentration was elevated in PF group compared to normal control $(\mathrm{p}=0.001)$, while there was a significant reduction of this fibrotic marker in metformin treatment group compared to PF group 
$(p=0.001)$, the reduction in TGF-b level in flaxseed oil treatment group was non-significant compared to PF group $(p=0.062)$, while the reduction was statistically significant in the combined treatment group $(\mathrm{p}=0.001)$ compared to PF group. (Table 4, figure 5).

Table (4): Effect of treatment with metformin and /or flaxseed oil on lung tissue homogenate fibrotic markers:

\begin{tabular}{|l|l|l|l|l|l|}
\hline $\begin{array}{c}\text { Group variable } \\
(\text { mean } \pm \text { SD })\end{array}$ & \multicolumn{1}{|c|}{ Control } & \multicolumn{1}{c}{ PF } & Met & Flax & \multicolumn{1}{c|}{ Met-Flax } \\
\hline Col- $\mathrm{I}(\mu \mathrm{g} / \mathrm{l})$ & $1.17 \pm 0.58$ & $4.16 \pm 0.52^{* *}$ & $1.01 \pm 0.57^{\# \#}$ & $1.9 \pm 0.80^{\# \#}$ & $1.04 \pm 0.57^{\# \#}$ \\
\hline TGF- $\beta(\mathrm{pg} / \mathrm{ml})$ & $8.6 \pm 0.98$ & $27.4 \pm 7.48^{* *}$ & $12.68 \pm 1.75^{\# \#}$ & $19.57 \pm 6.21$ & $11.87 \pm 2.18^{\# \#}$ \\
\hline
\end{tabular}

Values are mean $\pm \mathrm{SD}$, statistically significant difference, ${ }^{* *} \mathrm{p}, \# \# \mathrm{p}<0.01,\left({ }^{*}\right) .{ }^{*} \mathrm{P},{ }^{*} \mathrm{P}<0.05$ compared to control group, (\#) compared to PF group. Control: normal group, PF: bleomycin induced pulmonary fibrosis group, met: metformin treated group, Flax: Flaxseed treated group, Met-Flax: combined treatment group.
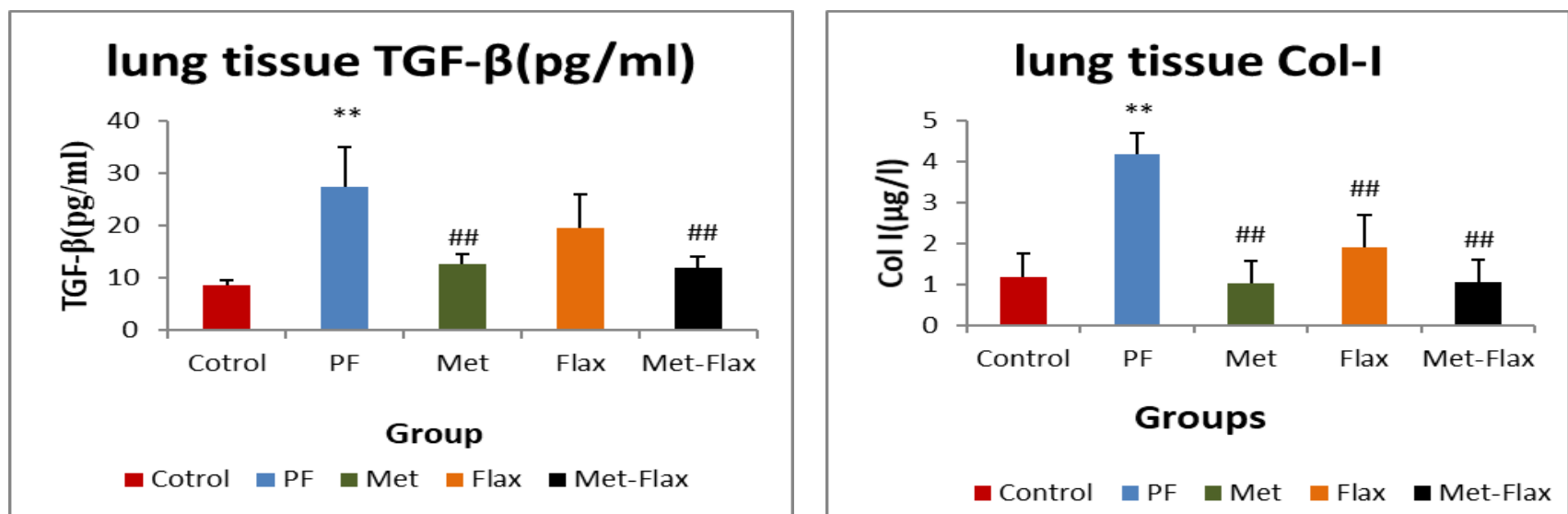

Fig.5: collagen I and transforming growth factor- $\beta$ by ELISA in lung tissue,

Values are mean $\pm \mathrm{SD}$, **p, \#\# $\left.\mathrm{p}<0.01,{ }^{*}\right) .{ }^{*} \mathrm{P},{ }^{\#} \mathrm{P}<0.05$ compared to control group, (\#) compared to $\mathrm{PF}$ group. Control:normal control group, PF:bleomycin induced pulmonary fibrosis group, Met:metformin treated group, Flax: Flaxseed treated group, Met-Flax:combined treatment group

\section{Effect of treatment with metformin and /or} flaxseed oil on lung tissue homogenate inflammatory markers

The level of inflammatory markers IL-6 and TNF- $\alpha$ in lung tissue shows significant elevation in bleomycin induced PF group compared to normal control $(\mathrm{p}=0.001)$, while treatment groups show significant reductions of both markers compared to PF group $(\mathrm{p}=0.001)$. We had also found that combined treatment group shows more reduction in inflamatory markers that was not significant compared to metformin treatment group $(\mathrm{p}=1)$ and significant compared to flaxeed treatment alone $(\mathrm{p}=.001)$. (Table 5, Figure $6)$.

\section{Effect of treatment with metformin and/or} flaxseed oil or combined treatment on lung NOX 4 gene expression:

The expression level of NOX4 by PCR showed statistically significant elevation in pulmonary fibrosis $(\mathrm{PF})$ group compared to normal control $(p=0.001)$ while it's expression was decreased in metformin treated, flaxseed treated and combined treated groups compared to disease control $(\mathrm{p}=0.001)$, the expression in both metformin treated group and combined treated group was non statistically significant from normal control $(\mathrm{p}=0.18, \mathrm{p}=.14)$ respectively. While in flaxseed treatment group it was statistically significant from normal control $(\mathrm{p}=0.001)$.* (Table 6 , Figure 7). 
Table (5): Effect of treatment with metformin and /or flaxseed oil on lung tissue homogenate inflammatory markers:

\begin{tabular}{|l|l|l|l|l|l|}
\hline $\begin{array}{l}\text { Group varable } \\
(\text { mean } \pm \text { SD) }\end{array}$ & $\underline{\text { Control }}$ & $\underline{\text { PF }}$ & $\underline{\text { Met }}$ & $\underline{\text { Flax }}$ & $\underline{\text { PF, CombinedMet- }}$ \\
\hline$\underline{\text { IL-6 }(\mathrm{pg} / \mathrm{ml})}$ & $17 \pm 7.87$ & $79.5 \pm 5.82^{* *}$ & $38 \pm 5^{\# \#}$ & $54.5 \pm 4.2^{\# \#}$ & $36 \pm 3.74^{\# \#}$ \\
\hline TNF- $\alpha(\mathrm{pg} / \mathrm{ml})$ & $\underline{14.5 \pm 4.32}$ & $\underline{109.17 \pm 9.70^{* *}}$ & $\underline{26.17 \pm 0.5^{0 \# \#}}$ & $\underline{64.8 \pm 3.5^{\# \#}}$ & $\underline{24.33 \pm 4.2^{\# \#}}$ \\
\hline
\end{tabular}

Values are mean $\pm \mathrm{SD}$, statistically significant difference, ${ }^{* *} \mathrm{p}, \# \# \mathrm{p}<0.01,\left({ }^{*}\right) .{ }^{*} \mathrm{P},{ }^{*} \mathrm{P}<0.05$ compared to control group, (\#) compared to PF group. Normal control group, PF: bleomycin induced pulmonary fibrosis group, met: metformin treated group, Flax: Flaxseed treated group, Met-Flax: combined treatment group.

Table (6): Effect of treatment with metformin and /or flaxseed oil on NOX4 gene expression

\begin{tabular}{|l|l|l|l|l|l|}
\hline $\begin{array}{l}\text { Group } \\
\text { variable } \\
\text { (mean } \pm \text { SD) }\end{array}$ & Control & PF & Met & Flax & $\frac{\underline{\text { PF, }}}{\frac{\text { combined }}{\text { Met-Flax }}}$ \\
\hline $\begin{array}{l}\text { Lung Nox4 } \\
\text { expression }\end{array}$ & $1.2 \pm 0.7$ & $21.59 \pm 4.6^{* *}$ & $5.14 \pm 1.76 \# \#$ & $9.33 \pm 2.62 \# \#$ & $5.29 \pm 1.8 \# \#$ \\
\hline
\end{tabular}

Values are mean $\pm \mathrm{SD}$, statistically significant difference, ${ }^{* *} \mathrm{p}, \# \# \mathrm{p}<0.01,\left({ }^{*}\right) .{ }^{*} \mathrm{P},{ }^{*} \mathrm{P}<0.05$ compared to control group, (\#) compared to PF group. Normal control group, PF: Bleomycin induced pulmonary fibrosis group, met: metformin treated group, Flax: Flaxseed treated group, Met-Flax: combined treatment group.
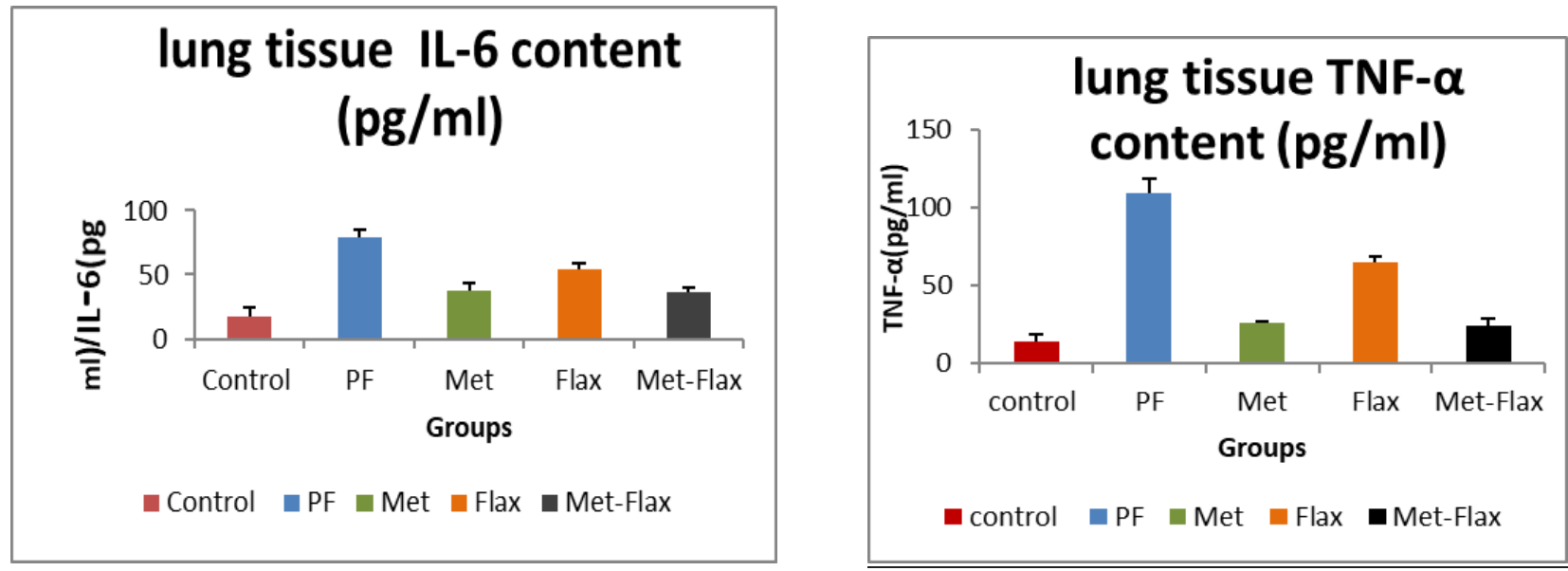

Fig.6: Mean value of lung tissue TNF- $\alpha$ (a) and IL-6(b), values are mean \pm SD, **p, \#\# p $<0.01,\left({ }^{*}\right)$. ${ }^{*}$, ${ }^{\#} \mathrm{P}<0.05$ compared to control group, (\#) compared to PF group. Control: normal control group, PF: bleomycin induced pulmonary fibrosis group, met: metformin treated group, Flax: Flaxseed treated group, Met-Flax: combined treatment group.

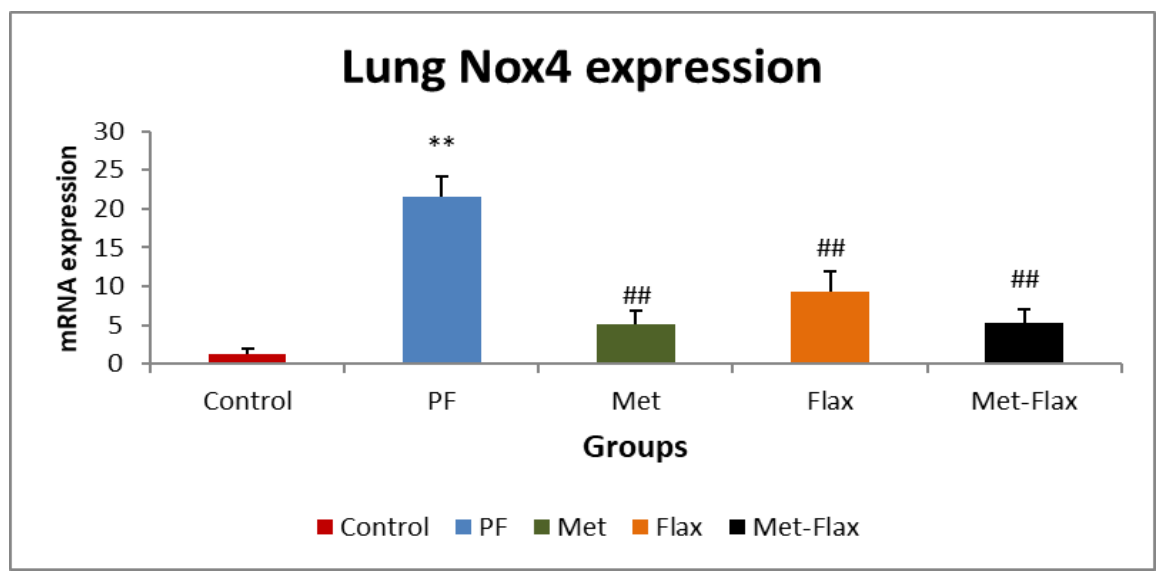

Fig.7: lung mRNA expression, values are mean $\pm \mathrm{SD},{ }^{*} \mathrm{p}, \# \# \mathrm{p}<0.01,(*)$. ${ }^{*} \mathrm{P},{ }^{\#} \mathrm{P}<0.05$ compared to control group, (\#) compared to PF group. Control: normal control group, PF: bleomycin induced pulmonary fibrosis group, met: metformin treated group, Flax: Flaxseed treated group, Met-Flax: combined treatment group. 


\section{Discussion}

Pulmonary fibrosis is a pathological result of a dysfunctional repair in response to tissue injury with several underlying etiologies as severe infection, radiation, chemotherapy, environmental exposure or unknown etiologies, as in idiopathic pulmonary fibrosis (IPF).the pathogenesis of fibrosis involve interaction between several factors that eventually lead to injury (17).

Metformin is a potent antidiabetic medication belongs to biguanide used to lower blood glucose in type II diabetes patients. Metformin exhibits pleiotropic effects on cellular biology, which is related to anti-inflammatory and antifibrotic propriety and reduced TGF- $\beta$-induced ECM protein production $(18,19)$.

Flaxseed or linseed (Linumusitatissimum L) a herb belonging to the Linaceae family. Flaxseeds is used as a source for oil and used in meal, flaxseed is rich in fiber, protein, and fat. Flaxseed oil is rich in polyunsaturated w-3, w-6 essential fatty acids (EFAs) as linolenic acid and linoleic acid, in addition to monounsatured w-9 fatty acids (MUFAs) as oleic acid. The flaxseed oil has several beneficial and disease preventive effects, which include hypocholesterolemic, anticancerous, antiviral effects, bactericidical activity, reduction of inflammation, hypoglycemic effects, laxative and cardio-protective and antidepressant effect (20-23)

The current study sheds light on the pulmonary protective potential of metformin and flaxseed oil against BLM-induced pulmonary fibrosis. In the current study, a well characterized rodent model involving single intratracheal instillation of BLM was adapted. BLM instillation significantly impaired biochemical dynamics, histopathological architecture with marked impairment of physiological pulmonary functions compared to normal as already demonstrated in the literature (24- 26)

In the present study, we demonstrated that metformin, flaxseed oil treatment significantly improved lung injury in BLM-treated rats. Indeed, both individually was equally beneficial in improving lung injury, including improvement of functional and structural changes and inhibition of fibrosis, inflammation, lipid accumulation in the lung. Dual therapy with metformin and flaxseed oil, insome, but not all aspects, produced additive and synergistic therapeutic effects in the treatment of lung fibrosis.

Pulmonary fibrosis pathogenesis involves variety of factors such as inflammation, ROS, activation of profibrotic cytokines. Among a variety of profibrotic cytokines is trans forming growth factor (TGF)- $\beta$ that play a crucial role in orchestrating fibrosis development during IPF pathogenesis through regulating myofibroblast differentiation and proliferation result in accumulation of excessive deposition of ECM proteins $(27,28)$

TGF $\beta$ stimulate biosynthesis of fibronectin and collagen; exert a powerful role in fibroblast proliferation. There is a positive correlation between the tissue levels of TGF $\beta$ and the severity of fibrosis induced by BLM, also, the role of TGF $\beta$ in the excessive synthesis of collagen in lung fibrosis is demonstrated, its attachment to its specific receptor type II favored the induction of the inflammatory response and subsequent installation of fibrosis (29). The inflammation probably create a microenvironment that promotes 
fibrosis by secreting growth factors, chemokines, cytokines and reactive oxygen species (ROS)(30).

TGF- $\beta$ induced cell signaling pathways is modulated via ROS, a major source of endogenous ROS production is NADPH oxidases (NOXes), among seven isoforms of NOXes, NOX4 is unique in that it is constitutively active, thus it's expression level is a major point of regulation NOX4 has been shown to modulate TGF- $\beta$ /SMAD-signaling via intracellular ROS production (31,32).

Increased expression levels of NOX4 have been reported in IPF lung not only in fibroblast of actively fibrosing areas but also injured epithelial cells , NOX4 is essential for a variety of issues include myofibroblast differentiation through TGF- $\beta$, apoptosis resistance by accelerating cellular senescence, which is associated with prolonged ECM production.(33-35) .NOX4 is implicated as both an upstream and a downstream mediator of TGF- $\beta$ mediated SMAD signaling(31). Our study found that level of TGF- $\beta$ and collagen type I was elevated in the BLM induced fibrosis group compared to normal control, associated with increased expression of NOX4 and elevated MDA level in the BLM induced fibrosis group compared to normal group with associated fibrosis appeared in histological sections while in the treatment groups it was found that TGF- $\beta$ and collagen type I level was reduced and NOX4 expression was decreased with subsequent decrease in MDA level and associated with reduced fibrosis in histological sections, with the metformin reducing TGF- $\beta$, collagen type I, and NOX4 expression a little more than flaxseed oil although the difference was nonsignificant the combined treatment group show a little bit more reduction than each individual drug regarding TGF- $\beta$, collagen.

Amara et al., (36) found increased NOX4 expression levels are also observed in fibroblasts of IPF lungs and in cells from IPF lungs. Sato et al., (37) reported that metformin is involved in the mechanisms for attenuation of TGF- $\beta$-induced myofibroblast differentiation in lung fibrosis through inhibiting NOX4 expression at mRNA and protein level with reduction in ROS production, and illustrated that also with TGF- $\beta$ treatment NOX4 is responsible for metformin-mediated ROS inhibition, metformin not only reduces the expression levels of NOX4 ,but also SMAD phosphorylation, and $\alpha \mathrm{SMA}$ with concomitant decrease of lung fibrosis in BLM treatment.

Choi et al., (38), found that metformin treatment decreased the mRNA expression level of TGF- $\beta$, collagen- 1 and other fibrotic markers in the lung tissue compared to the BLM treated mice with significant reduction of fibrosis and collagen deposition in histological sections. Li et al., (39) reported that metformin decreased TGF- $\beta$ induced pulmonary fibrosis in vitro with decreased TGF- $\beta$-induced expression of $\alpha$-actin and collagen 1A1, it was also shown that metformin have antifibrotic role and attenuates EGFR-TKI-induced exacerbation of pulmonary fibrosis and decreased TGF- $\beta$-induced pulmonary fibrosis in vivo and in vitro.

Rangarajan et al., (40) also reported decrease protein expression of collagen and other fibrotic markers with metformin treatment. AbdElmaaboud et al.,(41) reported decrease TGF$\beta$ with prophylactic and therapeutic metformin with reduced fibrosis score in histological section compared to BLM treatment. Lee et al.,(42) 
reported that flaxseed oil supplementation reduce fibrosis in a mouse model of thoracic radiation injury as shown with decreased expression of TGF-beta1. Abidi et al., (24) and Yacoubi et al., (43) reported fibrosis with elevated TGF $\beta$ density upon istullation of BLM that was reversed with flaxseed oil treatment.

BLM infusion is believed to induce oxidative stress and inflammation both motivate each other this result in severance of the injury/repair process with promotion of pulmonary fibrosis (44). Bleomycin derived ROS targeting several biomolecules such as nucleic acid, protein, lipid with concomitant lipid peroxidation resulting in biochemical, histopathological and physiological dysfunctions, markers of oxidative stress have been observed in the lungs of pulmonary fibrosis patients and eccentric antioxidant activity exacerbated pulmonary fibrosis in animal models (45).

In the current study, it was observed that intratracheal BLM instillation significantly compromised oxidants/antioxidants hemostasis as manifested by the significant elevation of lung MDA content and the concomitant reduction in GSH content. Similar observations made by previous researches gave ratification to the current thoughts $(24,26,46)$. Our group reported chronic lung inflammation confirmed by biochemical assessments and histopathological evaluations with BLM instillation. Regarding inflammatory cells there was an increase in total count with elevated neutrophil and lymphocyte in BLAF, with elevated inflammatory markers IL-6 and TNF- $\alpha$ and appearance of infiltrate with inflammatory cells in lung section of BLM treated group.
The treatment groups with metformin and flaxseed showed reduction in oxidative stress with potentiation of the anti-oxidative mechanisms as illustrated by reduction in the level of MDA and elevated level of GSH. All the inflammatory signs were improved upon treatment with metformin, flaxseed oil or combined treatment. Metformin and flaxseed oil treatment reduces total count, neutrophil and lymphocyte fraction compared to BLM treated group, associated with significant reduction of inflammatory markers level and reduction of inflammatory infiltrate in lung tissue with treatment either with each one alone or with combined treatment there was also reduction of the inflammatory infiltrate in the histological sections, both metformin and flaxseed oil were comparable to each other regarding reduction of MDA and elevation of GSH, while metformin reduce the level of inflammatory markers more than flaxseed oil combined treatment reduce itis level more compared to each one alone.

Wang et al., (47) reported that metformin treatment reduce MDA level and increase activity of SOD , MDA was significantly elevated while the activity of SOD was decreased in the LPSinduced mouse model, and this was accompanied by the infiltration of a large number of neutrophils into the pulmonary tissue and all improved with metformin.

Choi et al., (38) found that total count, neutrophils, and lymphocytes in the BALF were higher in the BLM treated mice compared to control and that metformin treatment in mice led to a significantly reduction in the total cell count compared with the BLM-treated group with reduced infiltration with inflammatory cells in sections from the metformin-treated mice 
compared to BLM-treated group. reported elevated TLC and increased neutrophil and lymphocyte with elevated TNF- $\alpha$ with BLM treatment while with metformin treatment either prophylactic or therapeutic reduce neutrophil fraction, while TLC was reduced significantly with prophylactic metformin (41).

Jangale et al., (48) suggest that BLM exposure caused the significant decrease in antioxidant enzyme activity and therefore an increase of lipid peroxidation. Flaxseed oil treatment was found to significantly decrease the level of MDA and increase the level of antioxidant enzyme SOD and catalase reversing effect of BLM on oxidative state, as oxidant-induced damage gives rise to a high level of inflammation, result in disruption, inflammatory infiltrate in the histopathological section flaxseed oil was shown to reverse this effect $(24,43)$.

Medhat et al., (49) reported decrease in MDA level and increase activity of SOD with flaxseed treatment in lung compared to the group where toxicity was induced by acute ethanol inhalation. Hussein et al.,(50) demonstrated that integration of flaxseed oil reduce level of MDA and increase level of GSH and activity Of SOD and modulates inflammatory and immune reactions, it is considered as a potential therapeutic agent for inflammatory and autoimmune diseases. as it decrease level of inflammatory mediators TNF- $\alpha$ and IL-1. In addition, it inhibits the generation of transforming growth factor- $\alpha$ (TGFa) due to n-3 PUFA-derived lipid mediators in experimental viral hepatitis.

Lawrenz et al., (25) found that that flaxseed oil was effective in protecting lung tissue against bleomycin-induced pulmonary toxicity in rats indicated by increased lumen patency and reduced pulmonary septal thickness, decreased inflammatory cell infiltrate, delayed edema formation, reduced vasculitis, and pulmonary and peribronchial fibrosis. Lee et al., (42) also found that dietary flaxseed decreases lung fibrosis and inflammation and oxidative stress in the lung $\mathrm{s}$ of mice with radiation induced pneumonopathy. Also, the anti-inflammatory effect of flaxseed was reported in liver (51).

The anti-fibrotic modality and antiinflammatory effect of metformin was also reported in heart, kidney and liver (52-55), also the anti-inflammatory and anti-proliferative effect of flaxseed oil was reported with lung, liver ,heart ( $51,56-58)$

Thus, the anti-fibrotic mechanism of metformin and flaxseed oil that is assigned to inhibition of TGF- $\beta$ mediated fibrosis and to it is effect in regulation of NOX4 expression and to reduction of NOX4 mediated ROS production with the anti-inflammatory effect that was obvious in the study may provide a treatment modality for lung fibrosis.

\section{References}

1.Wynn TA, Ramalingam TR. Mechanisms of fibrosis: therapeutic translation for fibrotic disease. Nat Med. 2012; 18:1028-1040. [PubMed: 22772564].

2. Lumeng CN, Saltiel AR. Inflammatory links between obesity and metabolic disease. J Clin Invest. 2011; 121:2111-2117. [PubMed: 21633179]

3. O'Neill LA, Hardie DG. Metabolism of inflammation limited by AMPK and pseudostarvation.Nature.2013; 493:346-355.

[PubMed: 23325217] 
4. Eltzschig HK, Eckle T. Ischemia and reperfusion--from mechanism to translation. Nat Med. 2011; 17:1391-1401. [PubMed: 22064429]

5. Hardie DG, Ross FA, Hawley SA. AMPK: a nutrient and energy sensor that maintains energy homeostasis. Nat Rev Mol Cell Biol. 2012; 13:251-262. [PubMed: 22436748]

6. Beers MF, Morrisey EE. The three R's of lung health and disease: repair, remodeling, and regeneration. J Clin Invest. 2011; 121:2065-2073. [PubMed: 21633173]

\section{Thannickal VJ, Zhou Y, Gaggar A, Duncan} SR. Fibrosis: ultimate and proximate causes. J Clin Invest. 2014; 124:4673-4677. [PubMed: 25365073] "Eicosapentaenoic acid prevents memory impairment after ischemia by inhibiting inflammatory response and oxidative damage," Journal of Stroke and Cerebrovascular Diseases, vol. 20, no. 3, pp. 188-195, 2011.

8. Yildirim Z1, Kotuk M, Iraz M, Kuku I, Ulu R, Armutcu F, Ozen S. Attenuation of bleomycin-induced lung fibrosis by oral sulfhydryl containing antioxidants in rats: erdosteine and $\mathrm{N}$-acetylcysteine.pulmonary pharmacology therapy. 2005;18(5):367-73. Epub 2005 Mar 23.

9. Nanda Gamada, Salma Malika, KapilSuchala, Swati Vasishta, AmeeshaTomara, SudheerAravab, Dharamvir Singh Aryaa, JagritiBhatiaa,Metformin alleviates bleomycin-induced pulmonary fibrosis in rats.Pharmacological effects and molecular mechanisms.2018.
10. Anouar Abidi,1 Raja Serairi,1 Nadia Kourda,2 Ridha Ben Ali,3Saloua Ben Khamsa1 and Moncef Feki4.Therapeutic effect of flaxseed oil on experimental pulmonary fibrosis induced by bleomycin in rats. European Journal of Inflammation. 2016, Vol. 14(2) 133-143.

11. Recep Akgedik,1 Şükran Akgedik,2 Harun Karamanlı,3 Sema Uysal,4 BülentBozkurt, DuyguOzol, Ferah Armutcu,4 and Zeki Yıldırım5,6 Effect of Resveratrol on Treatment of Bleomycin-Induced Pulmonary Fibrosis in Rats 2012. Inflammation, Vol. 35, No. 5, October 2012

12. Genovese T., Mazzon E., Di Paola R., Muia C., Crisafulli C., Caputi A.P., Cuzzocrea S. 2005b. Role of endogenous and exogenous ligands for the peroxisome proliferator-activated receptor alpha in the development of bleomycin-induced lung injury.Shock. 24:547-555.

13. Ashcroft, T., J.M. Simpson, and V. Timbrell. 1988. Simple method of estimating severity of pulmonary fibrosis on a numerical scale. Journal of Clinical Pathology 41: 467470.

14. Draper HH1, Hadley M.A review of recent studies on the metabolism of exogenous and endogenous malondialdehyde.Xenobiotica.1990 Sep;20(9):901-7.

15. Hübner R-H, Gitter W, Eddine El Mokhtari N, Mathiak M, Both M, Bolte H, et al. Standardized quantification of pulmonary fibrosis in histological samples. BioTechniques. 2008 Apr 1;44(4):507-17. 
16. Livak KJ, Schmittgen TD. Analysis of relative gene expression data using real-time quantitative PCR and the 2- $\Delta \Delta \mathrm{CT}$ method. methods. 2001;25(4):402-8.

17. King Jr TE, Pardo A, Selman M. Idiopathic pulmonary fibrosis. The Lancet. 2011 Dec 3;378(9807):1949-61.

18-Park, Chan Sun, Bang, Bo-Ram, Kwon, Hyouk-Soo, Moon, Keun-Ai, Kim, TaeBum, Lee, Ki-Young, Cho, You Sook. (2012). Metformin reduces airway inflammation and remodeling via activation of AMP-activated protein kinase. Biochemical pharmacology, 84(12), 1660-1670.

19-Park, Il-Ho, Um, Ji-Young, Hong, SungMoon, Cho, Jung-Sun, Lee, Seung Hoon, Lee, Sang Hag, \& Lee, Heung-Man. (2014). Metformin Reduces TGF- $\beta 1$-Induced Extracellular Matrix Production in Nasal Polyp-Derived Fibroblasts. Otolaryngology-Head and Neck Surgery, 150(1), 148-153.

20- Gomer, Richard H, \& Lupher Jr, Mark L. (2010). Investigational approaches to therapies for idiopathic pulmonary fibrosis. Expert opinion on investigational drugs, 19(6), 737-745.

21-Otranto, Marcela, Do Nascimento, Adriana Paulino, \& Monte-Alto-Costa, Andréa. (2010). Effects of supplementation with different edible oils on cutaneous wound healing. Wound Repair and Regeneration, 18(6), 629-636.

22- Han Y, Deng X, Zhang Y, Wang X, Zhu X, Mei S, Chen A. Antidepressant-like effect of flaxseed in rats exposed to chronic unpredictable stress. Brain and Behavior. 2020 Apr 19:e01626.
23- Han H, Qiu F, Zhao H, Tang H, Li X, Shi

D. Dietary flaxseed oil prevents western-type diet-induced nonalcoholic fatty liver disease in apolipoprotein-E knockout mice. Oxidative medicine and cellular longevity. 2017 Oct;2017.

24- Abidi, Anouar, Serairi, Raja, Kourda, Nadia, Ben Ali, Ridha, Ben Khamsa, Saloua, \& Feki, Moncef. (2016). Therapeutic effect of flaxseed oil on experimental pulmonary fibrosis induced by bleomycin in rats. European Journal of Inflammation, 14(2), 133-143.

25- Lawrenz, Joshua, Herndon, Betty, Kamal, Afrin, Mehrer, Aaron, Dim, Daniel C, Baidoo, Cletus, . . B Baybutt, Richard C. (2012). Dietary flaxseed oil protects against bleomycin-induced pulmonary fibrosis in rats. Pulmonary medicine, 2012.

26-Zaghloul, Marwa Salah, Abdel-Salam, Ramy Ahmed, Said, Eman, Suddek, Ghada Mohamed, \& Salem, Hatem AbdelRahman. (2017). Attenuation of Bleomycininduced pulmonary fibrosis in rats by flavocoxid treatment. Egyptian journal of basic and applied sciences, 4(4), 256-263.

27- Araya, Jun, \& Nishimura, Stephen L. (2010). Fibrogenic reactions in lung disease. Annual Review of Pathology: Mechanisms of Disease, 5, 77-98.

28- Xiao, Han, Ma, Xiaowei, Feng, Wei, Fu, Yongnan, Lu, Zhizhen, Xu, Ming, ... . Zhang, Youyi. (2010). Metformin attenuates cardiac fibrosis by inhibiting the TGF $\beta 1-$ Smad3 signalling pathway. Cardiovascular research, 87(3), 504-513. 
29- Calabresi, Carmen, Arosio, Beatrice, Galimberti, Lorenza, Scanziani, Eugenio, Bergottini, Raffaella, Annoni, Giorgio, \& Vergani, Carlo. (2007). Natural aging, expression of fibrosis-related genes and collagen deposition in rat lung. Experimental gerontology, 42(10), 1003-1011.

30- Bringardner BD, Baran CP, Eubank TD, Marsh CB. The role of inflammation in the pathogenesis of idiopathic pulmonary fibrosis. Antioxidants \& redox signaling. 2008 Feb 1;10(2):287-302.

31- Jiang, Fan, Liu, Guei-Sheung, Dusting, Gregory J, \& Chan, Elsa C. (2014). NADPH oxidase-dependent redox signaling in TGF- $\beta$-mediated fibrotic responses. Redox biology, 2, 267-272.

32-Martyn, Kendra D, Frederick, Linda M, von Loehneysen, Katharina, Dinauer, Mary C, \& Knaus, Ulla G. (2006). Functional analysis of Nox4 reveals unique characteristics compared to other NADPH oxidases. Cellular signalling, 18(1), 69-82.

33- Carnesecchi, Stephanie, Deffert, Christine, Donati, Yves, Basset, Olivier, Hinz, Boris, Preynat-Seauve, Olivier, Pache, JeanClaude. (2011). A key role for NOX4 in epithelial cell death during development of lung fibrosis. Antioxidants \& redox signaling, 15(3), 607-619.

34- Hecker, Louise, Vittal, Ragini, Jones, Tamara, Jagirdar, Rajesh, Luckhardt, Tracy R, Horowitz, Jeffrey C, Thannickal, Victor J. (2009). NADPH oxidase-4 mediates myofibroblast activation and fibrogenic responses to lung injury. Nature medicine, 15(9), 1077.
35- Jarman, Elizabeth R, Khambata, Valerie S, Cope, Claire, Jones, Peter, Roger, Jan, Ye, Li Yun, Press, Neil J. (2014). An inhibitor of NADPH oxidase-4 attenuates established pulmonary fibrosis in a rodent disease model. American journal of respiratory cell and molecular biology, 50(1), 158-169.

36- Amara, Nadia, Goven, Delphine, Prost, Fabienne, Muloway, Rachel, Crestani, Bruno, \& Boczkowski, Jorge. (2010). NOX4/NADPH oxidase expression is increased in pulmonary fibroblasts from patients with idiopathic pulmonary fibrosis and mediates TGF $\beta 1$-induced fibroblast differentiation into myofibroblasts. Thorax, 65(8), 733-738.

37- Sato, Nahoko, Takasaka, Naoki, Yoshida, Masahiro, Tsubouchi, Kazuya, Minagawa, Shunsuke, Araya, Jun, Kobayashi, Kenji. (2016). Metformin attenuates lung fibrosis development via NOX4 suppression. Respiratory research, 17(1), 107.

38- Choi, Sun Mi, Jang, An-Hee, Kim, Hyojin, Lee, Kyu Hwa, \& Kim, Young Whan. (2016). Metformin reduces bleomycininduced pulmonary fibrosis in mice. Journal of Korean Medical Science, 31(9), 14191425 .

39- Li, Li, Huang, Wenting, Li, Kunlin, Zhang, Kejun, Lin, Caiyu, Han, Rui, . . . Sun, Fenfen. (2015). Metformin attenuates gefitinib-induced exacerbation of pulmonary fibrosis by inhibition of TGF- $\beta$ signaling pathway. Oncotarget, 6(41), 43605.

40- Rangarajan, Sunad, Bone, Nathaniel B, Zmijewska, Anna A, Jiang, Shaoning, 
Park, Dae Won, Bernard, Karen, ... Mannon, Roslyn B. (2018). Metformin reverses established lung fibrosis in a bleomycin model. Nature medicine, 24(8), 1121-1127.

41- Abd Elmaaboud M, Balaha M, Abdelmonem F, Abdel-Rahman M, Hedeya S. Ameliorative potential of biguanides on experimentally-induced lung fibrosis. Bulletin of Egyptian Society for Physiological Sciences. 2019 Jun 1;39(1):102-17.

42- Lee JC, Krochak R, Blouin A, Kanterakis S, Chatterjee S, Arguiri E, Vachani A, Solomides CC, Cengel KA, ChristofidouSolomidou M. Dietary flaxseed prevents radiation-induced oxidative lung damage, inflammation and fibrosis in a mouse model of thoracic radiation injury. Cancer biology \& therapy. 2009 Jan 1;8(1):47-53.

43-Yacoubi, Lamia, Rabaoui, Lotfi, Hamdaoui, Mohamed Hédi, Fattouch, Sami, Serairi, Raja, Kourda, Nadia, \& Khamsa, Saloua Ben. (2011). Anti-oxidative and anti-inflammatory effects of Trigonella foenum-graecum Linnaeus, 1753 (Fenugreek) seed extract in experimental pulmonary fibrosis. Journal of Medicinal Plants Research, 5(17), 4315-4325.

44- Daba, Mohammed H, El-Tahir, Kamal E, Al-Arifi, Mohammed N, \& Gubara, Othman A. (2004). Drug-induced pulmonary fibrosis. Saudi medical journal, 25(6), 700706.

45- Chitra, Palanivel, Saiprasad, Gowrikumar, Manikandan, Ramar, \& Sudhandiran, Ganapasam. (2013). Berberine attenuates bleomycin induced pulmonary toxicity and fibrosis via suppressing NF- $\kappa \mathrm{B}$ dependant TGF- $\beta$ activation: a biphasic experimental study. Toxicology letters, 219(2), 178-193.

46- Verma, Ramesh, Kushwah, Lokendra, Gohel, Darpesh, Patel, Manish, Marvania, Tulsi, \& Balakrishnan, Suresh. (2013). Evaluating the ameliorative potential of quercetin against the bleomycin-induced pulmonary fibrosis in Wistar rats. Pulmonary medicine, 2013.

47- Wang G, Song Y, Feng W, Liu L, Zhu Y, Xie X, Pan Y, Ke R, Li S, Li F, Yang L. Activation of AMPK attenuates LPS-induced acute lung injury by upregulation of PGC1 $\alpha$ and SOD1. Experimental and therapeutic medicine. 2016 Sep 1;12(3):1551-5.

48- Jangale, Nivedita M, Devarshi, Prasad P, Dubal, Aarti A, Ghule, Arvindkumar E, Koppikar, Soumya J, Bodhankar, Subhash L, Harsulkar, Abhay M. (2013). Dietary flaxseed oil and fish oil modulates expression of antioxidant and inflammatory genes with alleviation of protein glycation status and inflammation in liver of streptozotocinnicotinamide induced diabetic rats. Food chemistry, 141(1), 187-195.

49- Medhat D, El-Khayat Z, El-Banna M, Abdel-Latif Y, Morsy S, El-Daly SM. Protective Effect of Polyunsaturated Fatty Acids Against Experimental Lung Injury Induced by Acute Ethanol Inhalation. Biomedical and Pharmacology Journal. 2019 Jun 25;12(2):533-8

50- Hussein J, Abo Elmatty D, Medhat D, Mesbah N, Farrag AR, Fahmy H. Flaxseed 
oil attenuates experimental liver hepatitis. Der Pharmacia Lettre. 2016;8(8):142-50.

51-Zhang X, Wang H, Yin P, Fan H, Sun L, Liu Y. Flaxseed oil ameliorates alcoholic liver disease via anti-inflammation and modulating gut microbiota in mice. Lipids in health and disease. 2017 Dec;16(1):1-0

53- Kim, Hyosang, Moon, Soo Young,

52- Bai, Jian, Zhang, Na, Hua, Ying, Wang, Bingjian, Ling, Lin, Ferro, Albert, \& Xu, Biao. (2013). Metformin inhibits angiotensin II-induced differentiation of cardiac fibroblasts into myofibroblasts. PloS one, $8(9)$.

53- Kim, Joon-Seok, Baek, Chung Hee, Kim, Miyeon, Min, Ji Yeon, \& Lee, Sang Koo. (2015). Activation of AMP-activated protein kinase inhibits ER stress and renal fibrosis. American Journal of Physiology-Renal Physiology, 308(3), F226-F236.

54- Zhang, Xiaodan, Harmsen, William S, Mettler, Teresa A, Kim, W Ray, Roberts, Rosebud O, Therneau, Terry M, Chaiteerakij, Roongruedee. (2014). Continuation of metformin use after a diagnosis of cirrhosis significantly improves survival of patients with diabetes. Hepatology, 60(6), 2008-2016.

55- Kita, Yuki, Takamura, Toshinari, Misu, Hirofumi, Ota, Tsuguhito, Kurita, Seiichiro, Takeshita, Yumie, Ando, Hitoshi. (2012). Metformin prevents and reverses inflammation in a non-diabetic mouse model of nonalcoholic steatohepatitis. PloS one, $7(9)$.

56 - Abidi A, Kourda N, Feki M, Ben Khamsa S. Protective effect of Tunisian flaxseed oil against bleomycin-induced pulmonary fibrosis in rats. Nutrition and Cancer. 2020 Feb 17;72(2):226-38.

57- Dupasquier CM, Dibrov E, Kneesh AL, Cheung PK, Lee KG, Alexander HK, Yeganeh BK, Moghadasian MH, Pierce GN. Dietary flaxseed inhibits atherosclerosis in the LDL receptor-deficient mouse in part through antiproliferative and antiinflammatory actions. American Journal of Physiology-Heart and Circulatory Physiology. 2007 Oct 1.

58-Kim, Hak-Ryul, Park, Byung-Kyu, Oh, Yeon-Mok, Lee, Yun-Song, Lee, DongSoon, Kim, Hyun-Kuk, Lee, Sang-Do. (2006). Green tea extract inhibits paraquatinduced pulmonary fibrosis by suppression of oxidative stress and endothelin-1 expression. Lung, 184(5), 287-295. 